Vol 14 Iss 13

Dec 2017
A Publication of the Systems and Psychosocial Advances Research Center

A Massachusetts Department of Mental Health Research Center of Excellence

\title{
The Impact of Health-Related Quality of Life on Retention in Drug Treatment Courts
}

\section{The Opioid Crisis}

With over 52,000 deaths a year, drug-related overdoses are the leading cause of accidental death in adults in the United States. ${ }^{1}$ In 2016 there were 1,990 confirmed deaths from opioid overdoses in Massachusetts, which is a $19 \%$ increase from $2015 .^{2}$ The opioid epidemic has resulted in national efforts to develop and implement scientificallybased and practical solutions to help individuals at highest risk for substance use and overdose, specifically those involved with the criminal justice system.

\section{Drug Treatment Courts \& Dropouts}

Research indicates that 50 to 70 percent of individuals involved with the criminal justice system meet criteria for substance use disorders and are at increased risk for overdose. ${ }^{3}$ In Massachusetts, former inmates who were recently released from prison were 56 times more likely to die of drug overdoses than community members who had not been recently incarcerated. ${ }^{4}$ Drug Treatment Courts (DTCs), specialty courts that mandate probationers to participate in substance use treatment, seek to aid this high risk population. DTCs are effective in reducing drug and alcohol use, ${ }^{5-8}$ but have early dropout (or failure to complete the program) rates as high as $75 \% .{ }^{6}$ Predictably, individuals who do not complete the Drug Treatment Program are more likely to continue using substances, have more frequent relapses, and continue to engage in high risk behaviors. ${ }^{6}$ Accordingly, identifying individuals most likely to dropout and helping them to remain in treatment programs is critical to decreasing substance use in this population.

\section{Role of Quality of Life in DTC Dropout}

Past research has focused on DTC dropouts as a function of participant characteristics (e.g., age, criminal history) or treatment program features (e.g., frequency of DTC hearings)..$^{8}$ Our study, The Impact of Health-Related Quality of Life on Retention in Drug Treatment Courts, proposes to shift the focus to health-related Quality of Life (QOL)

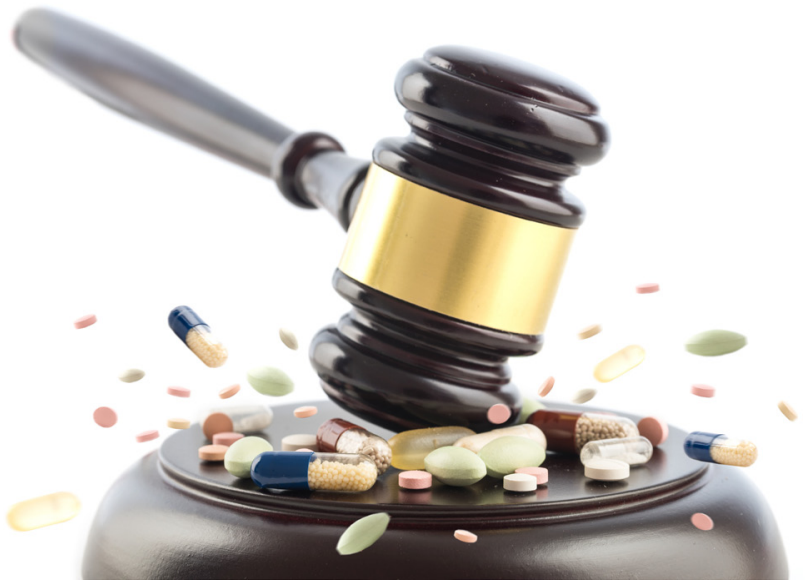

and its impact on dropout. QOL examines self-perceived physical and mental health and its effect on daily functioning ${ }^{9}$ and has been shown to predict retention in various treatment models. ${ }^{10-12}$ Federal agencies ${ }^{13}$ and researchers identify QOL as an important outcome of substance use treatment. Yet, QOL has never been examined in DTC participants.

We hypothesize that individuals who have worse QOL also have greater daily physical and emotional health difficulties, and thereby are less able to participate in DTCs, resulting in high rates of dropout. If we can use QOL to better identify individuals who are most likely to dropout of treatment, we can then develop interventions to improve individuals' overall functioning and QOL.

\section{Aims}

1. To evaluate the applicability and feasibility of QOL measures in Drug Treatment Courts populations.

2. To assess whether Drug Treatment Courts produce improvements in QOL and other psychosocial factors such as social support and self-efficacy about drug and alcohol abstinence.

3. To examine whether QOL can predict attrition from Drug Treatment Courts.

To this end, seven DTC participants will be asked to participate in a brief interview and complete self-report questionnaires at 3 
time points: 1) within one month of enrollment into a DTC, 2) at 6 months, and 3) at 12 months. Data will be collected to learn about what impacts the participant's QOL scores and other psychosocial variables, as well as retention in DTCs.

Our ultimate goal is to improve retention in DTCs and substance use treatment. Findings from this study will produce pilot data to aid in the development of an intervention to improve QOL and presumably retention in DTCs.

\section{Research Investigator:}

Ekaterina Pivovarova, Ph.D. (PI);

Funding \& Time Frame:

National Institutes of Health, 2017-2020;

Study Contact:

Ekaterina.Pivovarova@umassmed.edu

\section{References}

1. Rudd, R. A., Aleshire, N., Zibbell, J. E., \& Gladden, R. M. (2016). Increases in drug and opioid overdose deaths - United States, 2000-2014. Morbidity and Mortality Weekly Report (MMWR), 64(50-51), 1378-1382. doi:10.15585/mmwr.mm6450a3

2. Massachusetts Department of Public Health. (2017, August). Data brief: Opioid-related overdose deaths among Massachusetts residents. Retrieved from http://www.mass.gov/eohhs/docs/dph/stop-addiction/current-statistics/data-brief-overdose-deathsaug-2017.pdf

3. National Institutes of Health, Department of Health \& Human Services. (2014). Principles of drug abuse treatment for criminal justice populations: A research based guide. Retrieved from https://www.drugabuse.gov/publications/principles-drug-abusetreatment-criminal-justice-populations/principles

4. Massachusetts Department of Public Health. (2016). An assessment of opioid-related deaths. Retrieved from http://www.mass.gov/ eohhs/docs/dph/stop-addiction/chapter-55-opioid-overdose-study-data-brief-9-15-2016.pdf

5. DeVall, K. E., \& Lanier, C. L. (2012). Successful completion: An examination of factors influencing drug court completion for white and non-white male participants. Substance Use \& Misuse, 47(10), 1106-1116. doi:10.3109/10826084.2012.680171

6. Mitchell, O., Wilson, D. B., Eggers, A., \& MacKenzie, D. L. (2012). Assessing the effectiveness of drug courts on recidivism: A meta-analytic review of traditional and non-traditional drug courts. Journal of Criminal Justice, 40(1), 60-71. doi:10.1016/j. crimjus.2011.11.009

7. Wilson, D. B., Mitchell, O., \& MacKenzie, D. L. (2007). A systematic review of drug court effects on recidivism. Journal of Experimental Criminology, 2(4), 459-487. doi:10.1007/s11292-006-9019-4

8. Gallagher, J. R., Nordberg, A., Deranek, M. S., Ivory, E., Carlton, J., \& Miller, J. W. (2015). Predicting termination from drug court and comparing recidivism patterns: Treating substance use disorders in criminal justice settings. Alcoholism Treatment Quarterly, 33(1), 28-43. doi:10.1080/07347324.2015.982451

9. Center for Disease Control and Prevention. (2000, November). Measuring healthy days. Retrieved from https://www.cdc.gov/hrqol/ pdfs/mhd.pdf

10. Land, S. R., Walcott, F. L., Liu, Q., Wickerham, D. L., Costantino, J. P., \& Ganz, P. A. (2016). Symptoms and QOL as predictors of chemo-prevention adherence in NRG Oncology/NSABP trial P-1. JNCI Journal of the National Cancer Institute, $108(4)$, djv365. doi:10.1093/jnci/djv365

11. Younossi, Z. M., Stepanova, M., Henry, L., Nader, F., Younossi, Y., \& Hunt, S. (2016). Adherence to treatment of chronic hepatitis C: From interferon containing regimens to interferon and ribavirin free regimens. Medicine, 95(28), e4151. doi:10.1097/ MD.0000000000004151

12. Laudet, A. B., Becker, J. B., \& White, W. L. (2009). Don't wanna go through that madness no more: Quality of life satisfaction as predictor of sustained remission from illicit drug misuse. Substance Use \& Misuse, 44(2), $227-252$. doi: $10.1080 / 10826080802714462$

13. Tiffany, S. T., Friedman, L., Greenfield, S. F., Hasin, D. S., \& Jackson, R. (2012). Beyond drug use: A systematic consideration of other outcomes in evaluations of treatments for substance use disorders. Addiction (Abingdon, England), 107(4), 709-718. doi:10.1111/j.1360-0443.2011.03581.x 